\title{
Cyrillic Transliteration System Adopted in the Book
}

(adapted from ALA-LC Romanization Tables, Library of Congress)

\begin{tabular}{|c|c|c|c|}
\hline \multicolumn{2}{|c|}{ Russian } & \multicolumn{2}{|c|}{ English } \\
\hline Capital & Small & Capital & Small \\
\hline A & $\mathrm{a}$ & A & $\mathrm{a}$ \\
\hline Б & $б$ & B & $\mathrm{b}$ \\
\hline B & в & $\mathrm{V}$ & V \\
\hline$\Gamma$ & $\Gamma$ & G & G \\
\hline Д & д & $\mathrm{D}$ & $\mathrm{D}$ \\
\hline $\mathrm{E}$ & $\mathrm{e}$ & $\mathrm{E}$ & $\mathrm{e}$ \\
\hline Ж & ж & $\mathrm{Zh}$ & $\mathrm{zh}$ \\
\hline 3 & 3 & $Z$ & z \\
\hline$И$ and $\breve{И}$ & и and й & I & $\mathrm{i}$ \\
\hline K & К & K & $\mathrm{k}$ \\
\hline Л & л & $\mathrm{L}$ & 1 \\
\hline M & M & M & $\mathrm{m}$ \\
\hline $\mathrm{H}$ & H & $\mathrm{N}$ & $\mathrm{n}$ \\
\hline $\mathrm{O}$ & o & $\mathrm{O}$ & o \\
\hline$\Pi$ & п & $P$ & $\mathrm{p}$ \\
\hline $\mathrm{P}$ & $\mathrm{p}$ & $\mathrm{R}$ & $\mathrm{r}$ \\
\hline $\mathrm{C}$ & c & $S$ & $\mathrm{~s}$ \\
\hline $\mathrm{T}$ & $\mathrm{T}$ & $\mathrm{T}$ & $\mathrm{t}$ \\
\hline $\mathrm{y}$ & y & $\mathrm{U}$ & $\mathrm{u}$ \\
\hline$\Phi$ & $\phi$ & $\mathrm{F}$ & $\mathrm{f}$ \\
\hline $\mathrm{X}$ & $\mathrm{x}$ & $\mathrm{Kh}$ & $\mathrm{kh}$ \\
\hline Ц & ц & Ts & ts \\
\hline Ч & ч & $\mathrm{Ch}$ & $\mathrm{ch}$ \\
\hline Ш & ш & Sh & $\mathrm{sh}$ \\
\hline \multirow[t]{4}{*}{ щ } & щ & Shch & shch \\
\hline & $\mathbf{b}$ & & $"$ \\
\hline & Ы & & $\mathrm{y}$ \\
\hline & b & & , \\
\hline$\ni$ & э & $\dot{\mathrm{E}}$ & $\dot{\mathrm{e}}$ \\
\hline Ю & ю & $\mathrm{Iu}$ & iu \\
\hline Я & я & $\mathrm{Ia}$ & ia \\
\hline
\end{tabular}

(www.loc.gov/catdir/cpso/roman.html) 
